
complement to the class lectures and readings by establishing a tangible connection between their present experiences and their knowledge of Greek and Roman culture. The long-term project, thus, was intended to enhance the course material rather than replace it.

The construction of the mudbrick house also had a secondary aim. Its assembly contributed to Monmouth College's annual Classics Day events. The annual Classics Day, organised by Professor Robert Simmons, brings over 100 high school students, Latin teachers, college students, and local residents to the college's campus. During the day's events, visitors can witness 'more than two dozen individual events - including ancient Greek Olympics and Greek and Roman military demonstrations - that highlight and illuminate institutions and practices from the worlds of ancient Greece and Rome' (Monmouth College press report, $13^{\text {th }}$ April 2015). The culmination of my class' hands-on project was scheduled during this event: the assembly of the mudbrick structure in front of a large, public audience. By making the group project a component of this public festival, the construction also served as an interactive performance for the students to synthesise their experiences with the course lectures and answer questions from the audience about the project and ancient Greece.

\section{What is Hands-on Learning?}

Hands-on learning is instruction through doing (see, for example, Clarkson \& Shipton, 2015). With these exercises, students can engage directly and physically with objects to gain experiential knowledge about a certain topic or techniques. They also have an essential problem-solving component that requires students to think multi-dimensionally and transformatively about individual topics. Such learning through discovery is quite effective because it replicates the natural learning process of humans.

Hands-on learning has long served as a fundamental teaching tool in science curricula throughout the world (Lumpe \& Oliver, 1991; Flick, 1993; Haury \& Rillero, 1994; Triona \& Klahr, 2007; Bigler \& Hanegan, 2011). In this context, hands-on learning exercises allow students to 'actually [do] science' by recreating an experiment and seeing the results firsthand (Bigler \& Hanegan 2011, p. 246). When a primary school student adds vinegar to baking soda in the cone of a papier-mâché volcano to watch it 'explode', for example, $\mathrm{s} / \mathrm{h}$ witnesses a chemical reaction and connects the chemical equation to physical results. By making the subject matter less abstract through experimentation, students are more likely to make valuable, outside connections related to the course material, and ask more open-ended questions (Kirkpatrick, Orvis, \& Pittendrigh, 2002; Bigler \& Hanegan, 2011, p. 248). It also helps to reinforce the scientific method by successfully recreating a known experiment and employing standard procedures.

Taking a cue from their counterparts in sciences, archaeologists have recognised the potential of scientific experiment through recreation for assessing or revealing elements of the past that have long been assumed, hypothesised, and/or ignored (Coles, 1979; Clarkson \& Shipton, 2015). Because archaeology is the study of man's past activities' (Coles, 1979, p. 1), archaeologists can gather as much information as possible about a certain technique or topic, design an experiment, and test conceptualised hypotheses about possible actions in the past (Clarkson \& Shipton, 2015). This 'experimental archaeology' is now recognised as a viable research tool that can elucidate ancient methods which would otherwise be silent in the literary and archaeological record. As suggested by its name, however, this approach is rooted in the scientific tradition and places preference on novel discovery rather than the recreation itself as a tool for instruction. Hands-on learning, thus, occupies a fundamentally different role from experimental archaeology by placing a value on experience for demonstrating and disseminating known concepts and skills in the past (Clarkson \& Shipton, 2015).

In recent years, Classicists of all disciplines have not shied away from hands-on learning or immersive class exercises to engage with a broader public and demonstrate the appeal of ancient Greece and Rome. Individual classes, Classics Clubs, and Classics events throughout the world have invited participants and visitors alike to wear ancient clothing, eat fancy Roman delicacies like honeyed dormice, recreate hoplite military tactics, and engage in other such exercises. In a very 'meta' example, one school even used hands-on learning to recreate the ancient learning environment, the classroom (Dickey, 2015). These exercises, however, serve primarily to foster enthusiasm for the Classics by demonstrating ancient life through experiential learning. They are not necessarily designed as a valuable pedagogical tool for teaching broader concepts and skills.

I argue that Classicists should take inspiration from our science colleagues and use hands-on learning activities as an important tool for instruction. When designed correctly, hands-on learning projects can augment course lectures and themes while offering transferable skills and abilities, such as research and critical thinking, that are often sought in more exam- or paper-based assessments. In some circumstances, a hands-on project can even be preferred to traditional exercises by simulating real-world, group- and project-driven enterprises more accurately. All the while, these exercises engage students mentally and physically in a manner that can attract new students to Classics and maintain their interest over the long term.

\section{Goals}

An effective long-term hands-on learning project must have well-defined goals at the outset so that the project can contribute positively towards student education. For the mudbrick house project, I established the following goals:

1. Teach and reinforce essential research skills.

2. Foster practical, project-driven group work opportunities in which all students share equal responsibilities.

3. Provide a faithful recreation of ancient Greek architecture and construction.

Although Greek Cities was a halfsemester course, I considered it a fundamental responsibility to develop the students' research skills. This aim followed several of the established goals of both the department and the college. 
Table 1. | Assigned positions and responsibilities.

\begin{tabular}{|c|c|c|c|}
\hline \multicolumn{4}{|l|}{ Positions } \\
\hline Architekton & Hyparchitekton & Logothesios & Geometres \\
\hline Design synthesis & $\begin{array}{l}\text { Schedule meetings; } \\
\text { Organiser }\end{array}$ & Accountant; Supplier & $\begin{array}{l}\text { Measures all elements; } \\
\text { Surveys the construction site }\end{array}$ \\
\hline Kerux & Teichopoios & Plintheutes & Orofeutes \\
\hline Publicity & $\begin{array}{l}\text { Stone wall design and } \\
\text { construction }\end{array}$ & $\begin{array}{l}\text { Mudbrick design and } \\
\text { construction }\end{array}$ & $\begin{array}{l}\text { Thatch roofing design and } \\
\text { construction }\end{array}$ \\
\hline Rofopoios & Xylopoios & Epiplapoios & Ergastes \\
\hline $\begin{array}{l}\text { Design and construction of } \\
\text { roofing structure }\end{array}$ & $\begin{array}{l}\text { Woodworker for frames } \\
\text { and moulds }\end{array}$ & $\begin{array}{l}\text { Interior designer; } \\
\text { hearth builder }\end{array}$ & Labourer \\
\hline
\end{tabular}

Because the course only occupies a half-semester, however, lengthy research and writing assignments are difficult to be executed properly as effective learning exercises. With students researching construction, labour, and architecture and applying these to the hands-on project, however, they simulated synthetic research skills without developing a time-consuming and, often - from their perspective - 'boring', formal written response. In this way, the project served as a viable assessment alternative while still maintaining the essential teaching aims of my institution.

Because this project required collaboration from all students, it also offered a valuable opportunity to foster project-driven, group work. Although all students were required to contribute to the project, I wanted to ensure that they would all be shouldering an equal share of the work. To accomplish this, I distributed unique tasks to each student so that no two students researched or fulfilled the same role. The students understood that, because of their individualised roles in the project, the overall project success could only be met with complete participation and collaboration.

Most important, this project was designed to augment specific course lectures about daily life and architecture in ancient Greece. It was, thus, necessary that the class would produce a faithful recreation of past activities and material culture whenever possible. For this reason, ancient Greek literature and archaeology served as the fundamental inspiration for the design, and the skills that were practised for the project were strongly rooted in Greek and Roman culture.

\section{Project Design}

Before the half-semester course began, I carefully outlined in writing the goals of the hands-on learning exercise, the parameters for assessment, and the desired execution. This ensured that all the project's components complemented each other and the project served as a viable pedagogical exercise. At the outset of the project, students were also provided with a detailed overview that outlined the expectations and goals of the exercise.

At the same time, I assigned each student a unique position in the project. These positions corresponded to specific architectural components or organisational responsibilities. When possible, individual positions were named after specific types of labourers or craftsmen that existed in antiquity (Table 1). Students were then charged with researching that position and the architectural component under his/her purview and offering recommendations for the building design. The teichopoios, for example, oversaw the construction and design of the stone foundations. She researched the archaeological evidence for stone foundations, typical dimensions, and different construction techniques. For organisational roles, such as the architekton, the student researched the role of the architekton in antiquity and then fulfilled his planning function. In this case, the architekton collected the recommendations from all the other students, offered suggestions for the overall building design and dimensions, and made a complete blueprint for the design. By dividing the leadership positions among all the students, it ensured that the burden of the work would not fall unfairly upon the one or a small group of students.

Upon completion of the research, each student offered suggestions for the form, size, construction, and composition of the constituent part that s/he oversaw. These recommendations were accompanied by an annotated bibliography that described the primary evidence on which their suggestions were founded. This research phase, required the students to practise their research skills, synthesise this information, and apply it practically to an ongoing project. It also familiarised the students with archaeological field reports and primary literary sources. Such a detailed focus on ancient artefacts and design is difficult to achieve in a classroom setting without becoming overly pedantic. By creating a practical outlet for this research, however, the students engaged with research and primary sources in a more tactile and problem-solving manner.

After the initial research phase of the project, students were required to participate in several planning sessions prior to the Classics Day event. These sessions allowed the construction of several building elements that had to be prepared well in advance of the event. Mudbricks, for instance, require at least a week to dry and are very time-consuming to produce (approximately 24 per hour). For this project, the acquisition of materials, construction of wood elements (moulds), and the production of mudbricks occupied many of these planning sessions (Figure 1). For each element of construction, the students took instructions from the corresponding position leader. As an added benefit, these planning sessions also helped to bond the group together in advance of the public construction during Classics Day. By the event date, the students were familiar with each other and working cohesively in a group.

The final construction occurred during the Classics Day event. All students were required to attend and participate in the assembly of the structure. They were also asked to interact with the public audience and answer any questions from the attendees about the building or daily life in ancient Greece. This event offered an opportunity for public commendation for their efforts. 


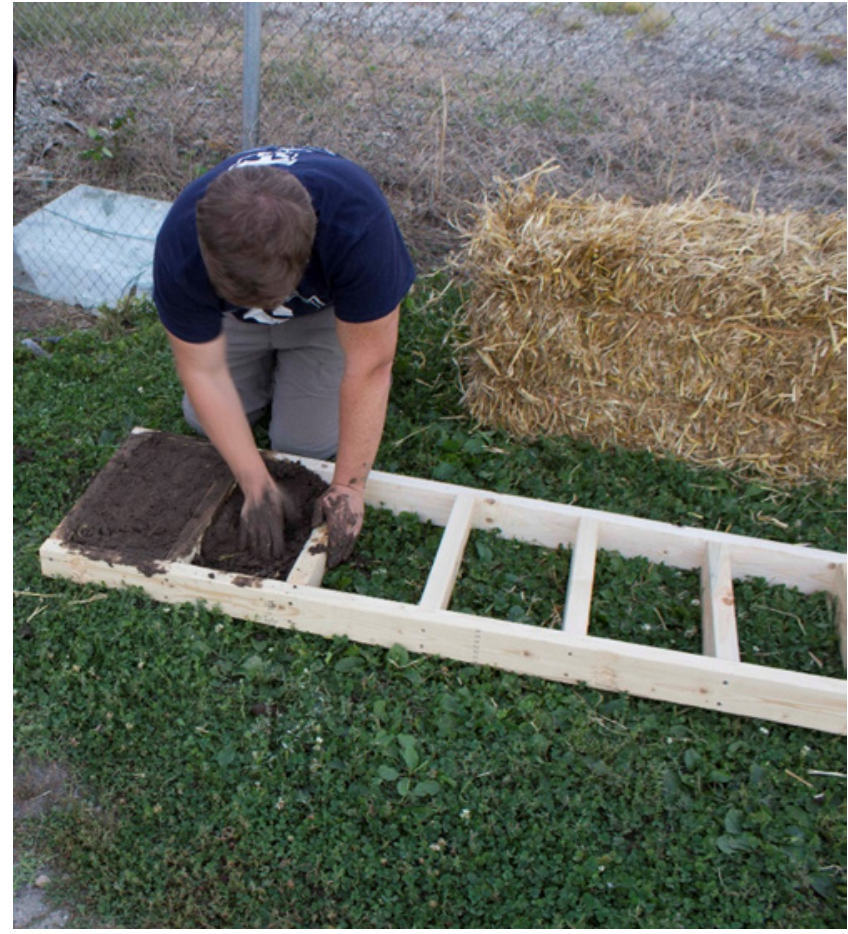

Figure 1. |Making mudbricks in a wooden mould.

\section{Assessment}

The project was composed of several individual components, each with accompanying individual grades or assessments. By distributing the grades among several, smaller assessments, I ensured that all students consistently participated throughout the duration of the project. Each graded component also provided constructive feedback to each of the students as the project progressed.

The graded research component of this project included an annotated bibliography and a short summary of project recommendations. These were accompanied by images or plans that complemented their recommendations and design. Students were required to consult a minimum of five sources, primarily from archaeological excavation reports or translations of ancient literary accounts. The absence of a formal written component ensured that the building design could be achieved as quickly as possible; the half-semester (seven weeks) course did not allow for simultaneous in-depth writing assessment and participation in multiple planning sessions. For this research component, students were graded on completion, research abilities (relevant sources), and faithfulness to the archaeological/literary evidence.
Another significant component to the grade was the participation credit. All the students had to attend one of two initial meetings in which we discussed the project, its research, and the building's design. Students were also required to attend at least two planning sessions to help with advance construction. To ensure that progress was made throughout the semester, I offered extra credit for participation in planning sessions beyond the required two. Finally, it was made clear that all students had to participate in the assembly of the building during the Classics Day festivities. Although students were graded on their presence at these sessions, it was understood that a lack of participation would be detrimental to their grades. The stated emphasis on participation, rather than writing, also helped to maintain the students' interest in the project.

\section{Professor's/Teacher's Responsibilities}

After the project design, the teacher's essential responsibilities include: time management, student assessment, external collaborations, and budget administration. S/he must also demonstrate to the students the individual components of the hands-on project when necessary. In this case, I showed the students the proper ratios of water / mud / straw and the kneading techniques for making mudbricks. The teacher must also take responsibility for the project funding and subsequent maintenance of the budget. Although I was not provided with a strict budget at the project's outset, I attempted to keep the costs as low as possible for the acquisition of project supplies. To do so, I talked with other departments at the college about donating spare materials. The Facilities

Management, for instance, allowed my class to use some of the college's left-over building supplies for the stone foundation. I also contacted a local donor to the college who agreed to donate several cubic meters of dirt from his farm for the construction. Because this was a student project with public presentation component, most people who were approached were happy to contribute to the success of the reconstruction. Finally, it was essential that I secured a safe location for the storage of the materials and messy preparation of the building elements, such as the mudbricks (Figure 2). This was achieved by contacting the campus Facilities Management office who offered space on college-owned land off-campus.

\section{Project Execution}

Students were asked to arrive at the preparation site prior to the scheduled events for the Classics Day in order to help move equipment and supplies. We were aware that our assembly would take longer than the allotted four hours of the festival and had arranged for an extended work day with the event and campus organisers. Even with the significant time commitment, all students contributed to the preparations without any difficulty or delay.

At the building site, the geometres followed the building plan to survey the site and place the first row of the stone wall on the ground (Figure 3). This row served as a guide for the subsequent courses of the stone and mudbrick wall. Students then contributed as a team to the movement of supplies and assembly of the building's walls (Figure 4). The students were already familiar with all the building supplies from their weeks of preparation 


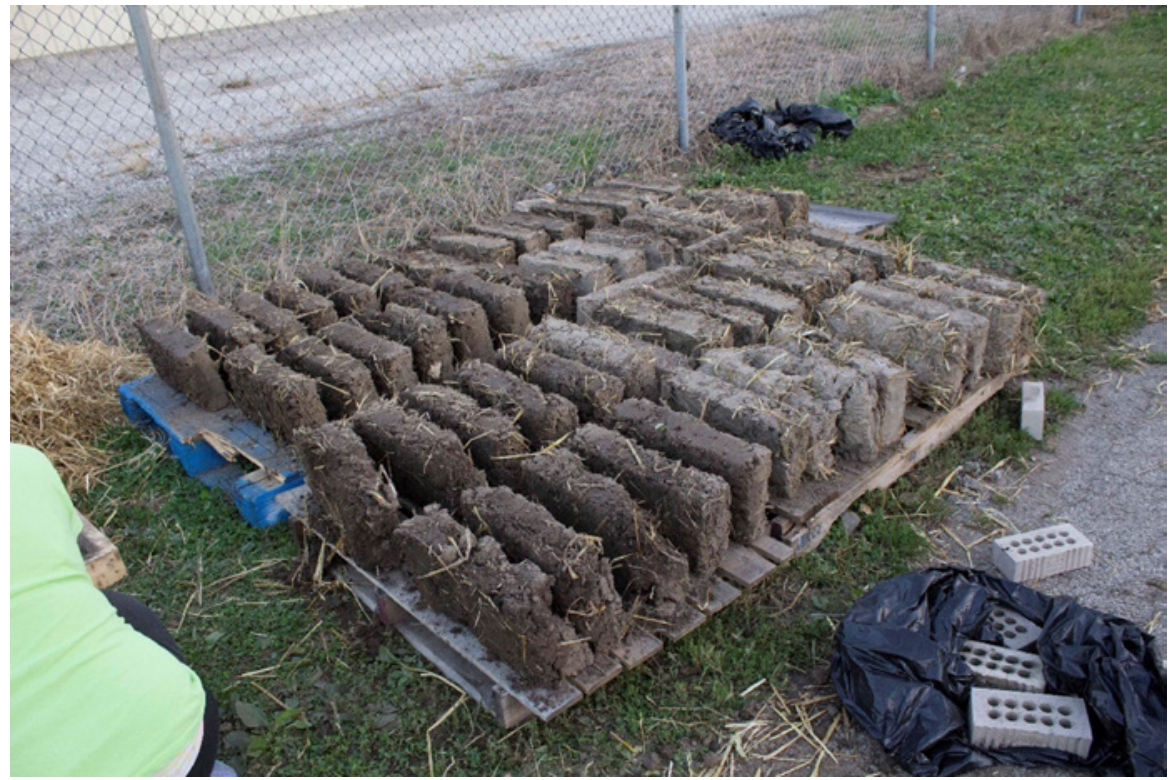

Figure 2.|Storage and drying of mudbricks at an off-campus facility.

and research into the constituent building parts. After having turned several mudbricks to help them dry, for instance, they understood the strength and durability of each piece, as well as their weight and stacking capabilities. As a result, they began construction without hesitancy. The students were also comfortable working with each other after having collaborated during the previous months' preparations. Little guidance besides initial instructions was required from the teacher; after the initial surveying, in fact, the group was almost entirely self-organising and self-reliant. The students' enthusiasm and concern also made it clear that they had become emotionally invested in the overall success of the project.

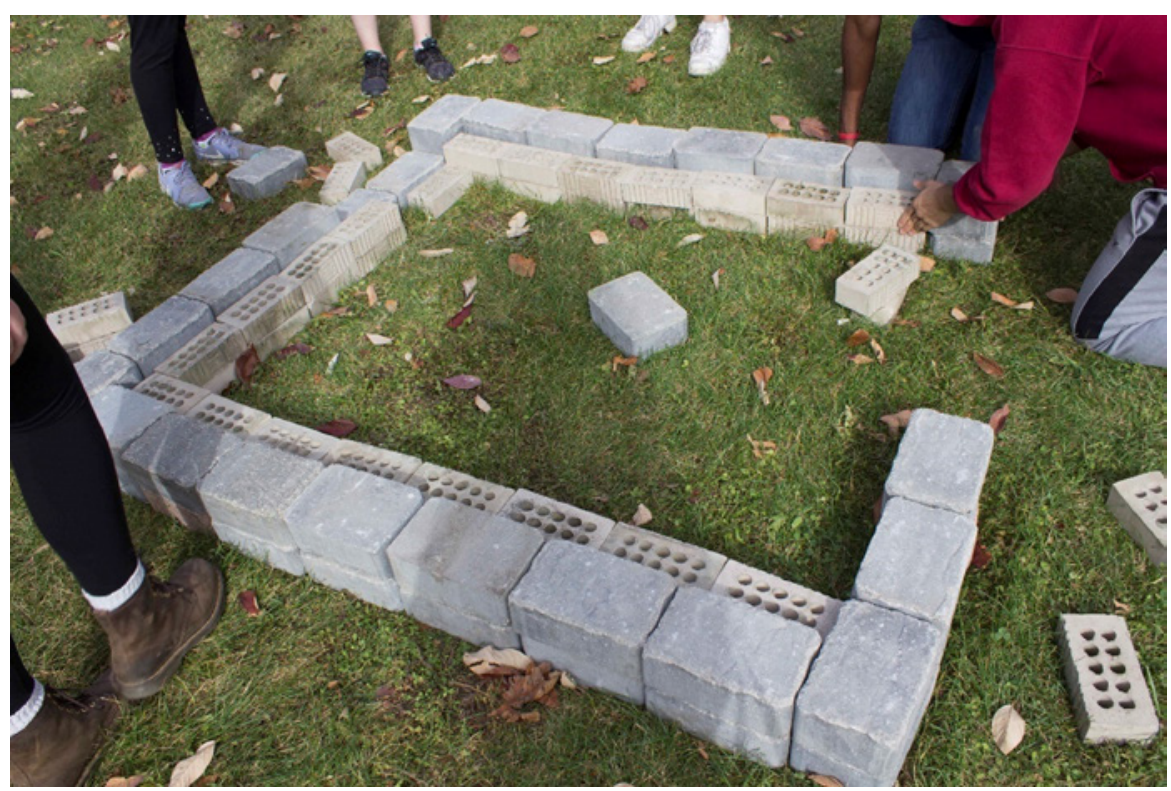

Figure 3.|The placement of the first courses of the small mudbrick house. wall course and subsequently initiate the roof construction. After the wooden roofing frame was placed on the walls, a mixture of clay and straw was packed over the wood. Because this clay and straw mixture resembled the mixture used for the mudbricks, the students were already practised in the necessary consistency of the clay and the correct techniques for kneading (Figure 5). Consequently, the roof construction and placement of the wooden framing elements went without a hitch despite the students' lack of advance preparation for this building element.

At the Classics Day event, the construction of the mudbrick structure was not an end unto itself, but it also served as a performance for the spectators. During this exhibition, the students had an important responsibility to demonstrate orally their newfound knowledge and experiences to the audience. As they worked on the construction, students were available to answer any questions about the construction efforts, daily life in Greece, and ancient Greek architecture. By the start of the festivities, the students had already engaged with the building material, construction and research and had developed the confidence to speak with authority on these topics. Their interaction with the attendees demonstrated the successful mixing of personal experience and knowledge of Classical sources - a fundamental goal of hands-on learning projects. This interaction also afforded the students an opportunity to reflect on their work and convey this knowledge through informal teaching.

\section{Difficulties}

Although the construction of the mudbrick structure was largely successful, there were a small number of difficulties encountered during this long-term project. Many of these, however, were beyond the control of the students or professor. For instance, rain often ruined mudbricks while they were drying. This required additional planning sessions that were readily attended after the lucrative promise of extra credit. Other difficulties were caused by occasional student neglect, such as missed research deadlines. After the construction of the building 


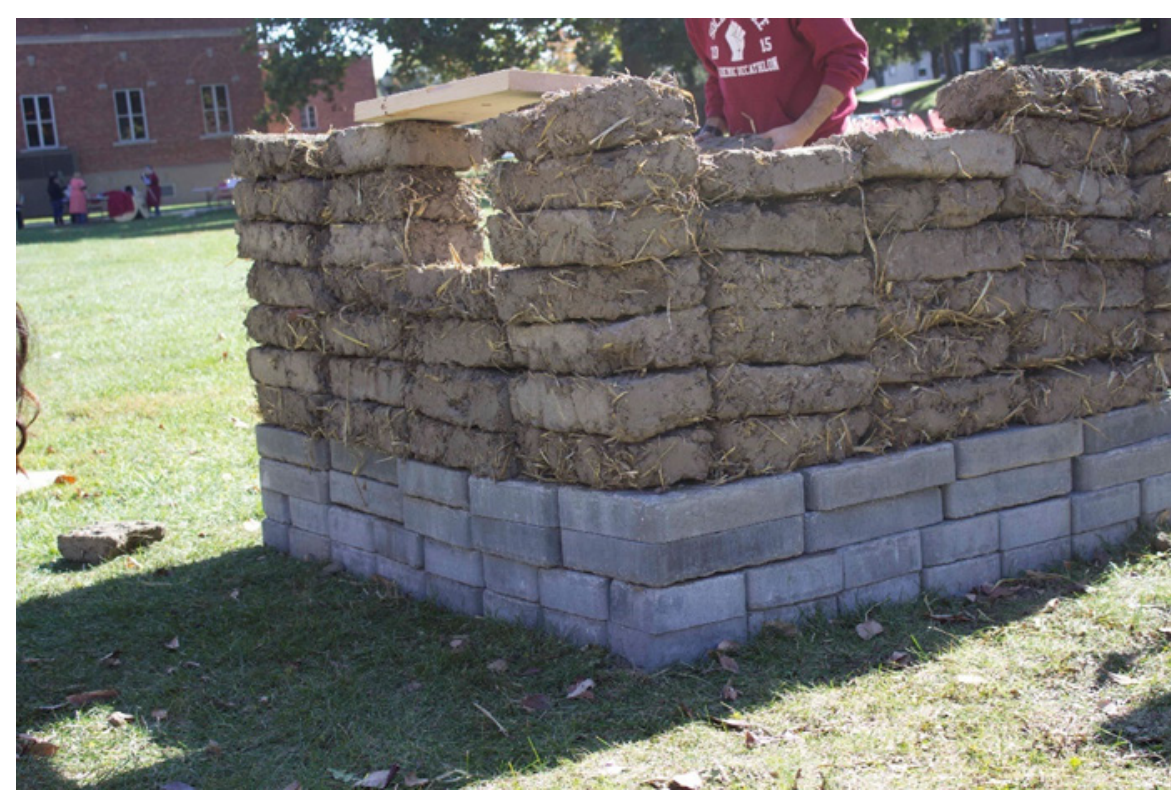

Figure 4. |The construction of the building's walls.

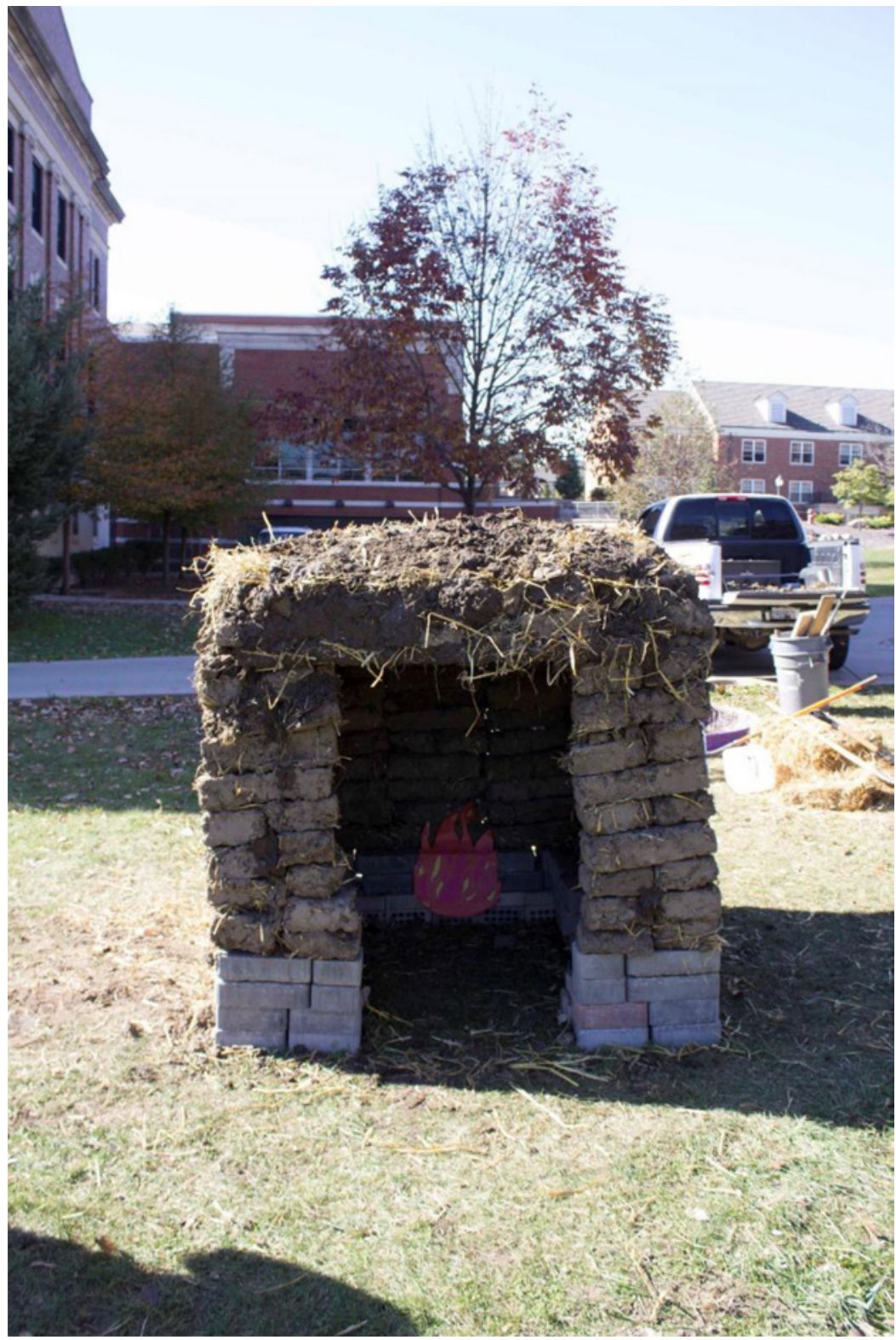

Figure 5. |The final mudbrick structure with a warm hearth placed inside. elements, however, the students were more present mentally and physically, prompting the late students to complete any outstanding background research. Last, there were some modest difficulties due to the building design. During the assembly on Classics Day, part of one mudbrick wall collapsed. This was largely caused by the uneven ground and was immediately rectified by re-engineering the placement of the mudbricks into a lattice arrangement that afforded greater structural integrity. In general, very few of these difficulties were the result of an inadequate project design. The frequent planning meetings, discussion, and participation helped the teacher and the class to anticipate any problems and augment the design and organisation as necessary.

\section{Reflection}

During the final class meeting of the half-semester, students were asked to reflect on their experiences with the project and their new knowledge of Greek architectural construction. This activity allowed the students to synthesise much of their learning from the course, thereby reinforcing their experiences and learning together in their memories. Without exception, the students expressed newfound appreciation for ancient architecture. They also more confidently stated their opinions about topics in the course and Classical culture. Because the activity was fundamentally grounded in the source material, the students could demonstrate tangible connections that existed in their mind between their personal experiences and the source material. During a short presentation in which I showed images of architectural remains, the students could easily identify building components and their function in the structures. Students were also provided with a final opportunity to ask open-ended questions about Greek architecture and the Classical world.

\section{Conclusions}

I was quite satisfied with the outcome of this long-term hands-on learning project. Through careful design, the project 
augmented the students' in-class learning experiences by providing an alternative approach to the development of critical thinking and research skills. The collaborative nature of the exercise also demanded project-driven group work from the students that replicated real-world activities and responsibilities.

Thus, the success of the mudbrick house construction was met equally by the final standing structure and the pedagogical benefits from their participation.

The project also relied on a close relationship with the primary evidence from the ancient world: Classical literature and archaeology. I have shown that Classics can rely on hands-on activities not only to attract interest and potential students, but also to serve as a productive learning pursuit. By learning through action, Classics can reveal many aspects of life in ancient Greece and Rome. With its close connection to experimental archaeology, hands-on learning can also provide particularly interested students with opportunities to continue their research and make positive scholarly contributions to the field with more advance recreations.

Kyle Alexander Jazwa is currently
a Visiting Lecturer in Greek
Archaeology at Duke University.
For the 2016-2017 academic year,
he was a Lecturer at Monmouth
College. He hold a Ph.D. in
Classical Archaeology from
Florida State University (2016). His
research predominately focuses
on ancient Greek architecture,
material production, and identity.
kyle.jazwa@duke.edu

\section{References}

Bigler, A. M., \& Hanegan, N. L. (2011). Student content knowledge increases after participation in a hands-on biotechnology intervention. Journal of Science Education and Technology, 20(3), 246-257.

Clarkson, C. \& Shipton, C. (2015). Teaching ancient technology using 'hands-on' learning and experimental archaeology. Ethnoarchaeology, 7(2), 157-172.

Coles, J. M. (1979). Experimental archaeology. London: Academic Press.

Dickey, E. (2015). An immersion class in ancient education. Journal of Classics Teaching, 16(31), 38-40.

Flick, L. B. (1993). The meanings of hands-on science. Journal of Science Teacher Education, 4, 1-8.

Haury, D. L. \& Rillero, P. (1994). Perspectives of hands-on science teaching. Columbus, OH: ERIC Clearing House for Science, Mathematics, and Environmental Education.

Kirkpatrick, G., Orvis, K., \& Pittendrigh, B. (2002). A teaching model for biotechnology and genomics education. Journal of Biological Education, 37(1), 31-35.

Lumpe, A. T. \& Oliver, J. S. (1991).

Dimensions of hands-on science. The American Biology Teacher, 53, 345-348.

Triona, L. M. \& Klahr, D. (2007). Hands-on science: does it matter what students' hands are on? The Science Education Review, 6(4), 126-130. 